\title{
A expressão verbal a serviço do efeito de sentido metafórico
}

The verbal expression of the service the effect of the methaforic meaning

\author{
Angela Cristina Di Palma Back \\ Universidade Federal de Santa Catarina - UFSC \\ Universidade do Extremo Sul Catarinense - UNESC
}

Abstract

This study focuses on the uses of the past imperfect tense of the subjunctive according to data provided by VARSUL, ${ }^{1}$ on the basis of Bello's prepositions (1979 [1841], 1984 [1847]) regarding Spanish. In this sense, an analysis semantic-pragmatic has been conducted in order to interpret the evidence furnished by the Portuguese florianopolitano which shows a metaphoric process at work.

\section{Keywords}

Past imperfect tense of the subjunctive, Verbal tense, Metaphoric use, Semantics, Pragmatics.

\section{Resumo}

Focalizam-se, neste estudo, usos do pretérito imperfeito do subjuntivo em dados do VARSUL, ${ }^{2}$ com base no que propõe Bello (1979 [1841], 1984 [1847]) para o espanhol. Para tanto, pautamo-nos em uma análise semântico-pragmática para a interpretação de evidências do português florianopolitano, mostrando um processo de metaforização em curso.

\section{Palavras-chave}

Pretérito imperfeito do subjuntivo, Tempo verbal, Uso metafórico, Semântica, Pragmática. 


\section{Introdução}

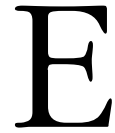

ste artigo visa ao estudo dos valores metafóricos (VMs) atribuídos a formas verbais, em uso no português, do pretérito imperfeito do subjuntivo, com vistas a averiguar em que medida tais valores decorrem das expressões das modalidades enunciativas, indo além dos limites descritivos da tradição gramatical.

Para tanto, tomaremos a teoria de tempo de Bello (1979 [1841], 1984 [1847]) como fio condutor deste estudo, mostrando que ela se mostra adequada o suficiente para analisar os dados em uso do português, a exemplo do que o autor faz para o espanhol, ao lidar também com evidência real, tomada de exemplos de literatos hispânicos. Isso se faz considerando o fato de que as duas línguas (português e espanhol) são contrastáveis sob os parâmetros da análise de ambos os paradigmas verbais, mas não se esgota nisso, uma vez que nos propomos a reconstruir o paradigma dessas formas verbais com base no uso, pautados em uma análise que requer o contexto semântico-pragmático para a interpretação.

O trabalho se divide em quatro seções. A primeira justifica a escolha do corpus que se utiliza da língua oral, bem como os critérios de seleção das ocorrências. A segunda seção expõe a base teórica de Bello desde sua interpretação das formas inseridas no eixo temporal até seus possíveis efeitos de sentido em que focaliza os VMs. A metáfora como expressão de valor decorrente da categoria de modalidade verbal é abordada na seção três, a partir da qual se rediscute os VMs com base no autor, focalizando evidências reais do português. A quarta seção visa a expor os VMs atribuídos especificamente à forma do pretérito imperfeito do subjuntivo (PIS). Por fim, tecemos, nas considerações finais, a base filosófica do autor, correlacionando-a ao modo de pensar a interpretação de tempo e postulando um percurso de ampliação semântica que se desloca do subjuntivo comum, portando o traço de [+ certeza], passando pelo subjuntivo hipotético [- certeza], chegando ao final com os VMs, mostrando, queremos crer, um processo de metaforização em curso relativo ao subjuntivo. 


\section{Medologia}

Bello pontua a importância em se olhar para os usos concretos da língua; frisa, ainda, que, por meio da observação do uso popular, se verifica a ordem (sistematicidade, regularidades), embora essa se apresente como uma desordem aos olhos de leigos, pois a compreensão de sua organização requer análise criteriosa.

En las sutiles y fugidias analogías de que depende la elección de las formas verbales ( $\mathrm{y}$ otro tanto pudiera decirse de algunas otras partes del lenguaje), se encuentra un encadenamiento maravilloso de relaciones metafísicas, eslabonadas con un orden y una precisión que sorprenden cuando se considera que se deben enteramente al uso popular, verdadero y único artífice de las lenguas (1979 [1841], p. 416 - Prólogo). ${ }^{3}$

A aparente desordem também se aplica ao sistema verbal, cuja análise sistematizada se faz necessária a fim de posicionar o valor efetivo das formas verbais, considerando a língua em uso, a exemplo do que o autor cita acima. É a partir do uso que se passa, então, a reconstruir paradigmas.

Segundo o autor, é possível verificar na aparente desordem da língua um sistema que apresenta uniformidade suscetível à aplicação de fórmulas rigorosas que se combinam e se decompõem. $\mathrm{O}$ uso concreto a que o autor se refere e toma como amostra para análise parte de exemplos do castelhano com base na literatura hispânica, propondo-se observar o funcionamento verbal focalizando esse uso. Nossa amostra toma como base também o uso concreto, mas o faz considerando a fala espontânea do português do Brasil, ou seja, a linguagem ordinária do cotidiano da região Sul do país. A amostra constituiu-se de quatro entrevistas de narrativas pessoais, selecionadas aleatoriamente, nas quais encontramos oito dados com VMs.

\section{Tempo verbal em Bello: da expressão de tempo à expressão metafórica}

Os enunciados podem descrever mais de um evento em que a ordenação temporal se torna complexa. Comumente, tais eventos são ordenados relativamente ao momento de enunciação, contudo há situações em que os eventos, ou melhor dizendo, os estados de coisas são ordenados uns relativamente aos outros (MATEUS et al., 1983), o que requer marcação mais complexa quanto à expressão temporal. 
É consensual entre os teóricos que abordam as relações de tempo, sem entrar no mérito da distinção quanto à orientação teórica de cada um deles (COMRIE, 1990; FIORIN, 1996; GIVÓN, 1984, 1993;LYONS, 1977; REICHENBACH, 1947), que as indicações de anterioridade, simultaneidade e posterioridade ao tempo de fala fornecem três tempos verbais, presente, passado e futuro, respectivamente. Em Bello, esses três momentos são nomeados de anterioridade (A), coexistência (C) e posterioridade $(\mathrm{P})$ ao momento de fala, tomados para representar relações temporais simples e complexas ${ }^{4}$ por meio da expressão de uma forma verbal simples, como esboça a quadro a seguir.

\section{QUADRO 1}

Relação temporal com base em Bello (1979 [1841], 1984 [1847]) - esboço de relações simples e complexas

\begin{tabular}{llll}
\hline RELAÇÕES & Coexistência & Anterioridade & Posterioridade \\
DE TEMPO & & \\
\hline Simples & Presente $(\mathrm{C})$ & Passado (A) & Futuro (P) \\
Complexa & Co-pretérito $(\mathrm{CA})^{5}$ & Pós-pretérito (PA) \\
\hline
\end{tabular}

Soma-se às relações traçadas, no Quadro 1, o traço de anterioridade (A) quando a língua expressa o tempo por meio de formas compostas, resultando novas fórmulas como o antepresente (AC) e o ante-co-pretérito (ACA) no eixo da coexistência, o antepassado (AA) no eixo da anterioridade e, por fim, o antefuturo (AP) e ante-pós-pretérito (APA) no eixo da posterioridade. Trata-se de fórmulas esquemáticas visando a representar relações complexas de tempo, o que se desdobra cf. o quadro seguinte.

\section{QUADRO 2}

Relação temporal com base em Bello (1979 [1841], 1984 [1847]) - esboço de relações complexas

\begin{tabular}{lccc}
\hline RELAÇÕES & Coexistência & Anterioridade & Posterioridade \\
DE TEMPO & Ante-presente & Ante-passado & Ante-futuro \\
Complexas - & (AC) & (AA) & \\
$\begin{array}{l}\text { envolvendo } \\
\text { formas compostas }\end{array}$ & Ante-co-pretérito & & Ans-pretérito \\
Complexa & (ACA) & & \\
\hline
\end{tabular}


A organização da seção que trata do subjuntivo em Bello (1979 [1841], 1984 [1847]), diferentemente do indicativo, não se divide em tempos primitivos ${ }^{7}$ e secundários, mas em subjuntivo comum e subjuntivo hipotético. Entretanto, observa-se simetria quanto ao número de valores temporais que as formas podem assumir entre o indicativo, com destaque para amo, amaba, he amado e había amado, e o subjuntivo (ame, amase ou amara, haya amado, hubiese ou hubiera amado), cf. quadro a seguir, proposto por Back et al. com base na interpretação do estatuto teórico do próprio autor.

\section{QUADRO 3}

Valores primitivo e secundário atribuídos ao indicativo e, por extensão, ao subjuntivo

\begin{tabular}{|c|c|c|c|c|c|c|c|}
\hline & Forma & $\begin{array}{l}\text { lor } \\
\text { hitivo }\end{array}$ & $\begin{array}{c}\text { Valor } \\
\text { secundário }\end{array}$ & & Forma & $\begin{array}{r}\text { Valor } \\
\text { primitivo }\end{array}$ & $\begin{array}{c}\text { Valor } \\
\text { secundário }\end{array}$ \\
\hline \multirow{4}{*}{ 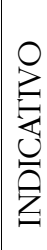 } & Amo & $\mathrm{C}$ & $\mathrm{CP}$ & & Ame & $\mathrm{C}$ & $\mathrm{P}$ \\
\hline & Amava & CA & CPA & 主 & Amase & A $C A$ & \\
\hline & He amado & $\mathrm{AC}$ & $\mathrm{ACP}$ & $\sqsupseteq$ & Hay amado & $\mathrm{AC}$ & $\mathrm{AP}$ \\
\hline & Habia amado & ACA & ACPA & $\frac{n}{\infty}$ & $\begin{array}{l}\text { Hubiese ou } \\
\text { bubiera amado }\end{array}$ & $\mathrm{AA}, \mathrm{ACA}$ & APA \\
\hline
\end{tabular}

Iniciamos nossa averiguação a partir da proposta feita por Bello (1979 [1841], 1984 [1847]), para o espanhol. Isso se faz considerando o fato de que o autor, embora tenha uma proposta assentada no racionalismo, em que tenta encontrar simetria formal nas interpretações de tempo e até use fórmulas, pauta suas considerações acerca dos valores atribuídos às formas verbais em análises que levam em conta o contexto semântico-pragmático para a interpretação. $\mathrm{O}$ autor o faz com base em evidências reais, i.e., no uso, a partir do qual se analisou a forma do (PIS) inserida nos modos subjuntivo comum, subjuntivo hipotético e na seção que tratou dos (VM), como mostram, respectivamente, os exemplos extraídos do próprio autor ao tratar desses valores:

(1) Los antiguos no imaginaron que la zona tórrida fuese habitable. (BELLO, 1979 [1841], p. 430) ${ }^{8}$

(2) Dijérome (los mercadores murcianos a D. Quijote) que les mostrase aquela senora, que si ella fuese tan hermosa como su merced significaba, de buena gana, confesarían la verdad. (BELLO, 1979 [1841], p. 432) ${ }^{9}$ 
(3) “...La muerte le diera

Con mis manos, si pudiera"10 (Calderón apud BELLO, 1979 [1841],p. 448)

Em (1), o tom é de asseveração, o que reveste o enunciado de uma certeza factual, e, com isso, licencia a comutação de FUESE (subjuntivo) por ERA (indicativo), perfil característico do subjuntivo comum. Quanto ao (2), tratase do subjuntivo hipotético, caracterizando-se como hipótese futura, e que, portanto, a partir de sua interpretação, não permite a comutação por forma do indicativo. Por fim, o pretérito posto em (3) sugere a idéia de negação implícita, no qual o valor temporal se torna irrelevante. ${ }^{11}$ Este estudo focaliza o último (3), correlacionando-o ao que ocorre com o português, como trata a sessão a seguir.

\section{VMs: modalidade como desencadeador do processo}

Dado que o tempo verbal é uma das várias estratégias desenvolvidas para codificar o tempo (COAN et al., 2003), estão associadas a ele outras categorias, por exemplo, a modalidade que envolve a atitude tomada (modus) pelo falante para com o conteúdo (dictum) que enuncia (DUCROT; TODOROV, 1972). A partir dessa categoria, pode-se interpretar exatamente as mesmas relações na escala temporal, porém com significado modal distinto, daí termos ora o traço de maior certeza ora de menor, ou outros traços modais que envolvem a gentileza, a proteção da face, ${ }^{12}$ etc, marcada, por vezes, no nível estrutural da língua e, por outras, no discursivo ${ }^{13}$ (BACK et al., 2005). Vejamos os exemplos a seguir que evidenciam ambas as ancoragens interpretativas (estrutural e discursiva):

(4) Aí ela estava apavorada não tem? Aí ela me aconselhou que eu TIRASSE. ${ }^{14}$ (L.18)

O exemplo (4) assinala uma incerteza expressa precisamente pelo "tirasse", sobre o qual podemos atribuir a interpretação irrealis, focalizada na possibilidade de ela (a informante) levar a cabo o conselho que é fato atribuído a sua interlocutora. Destaca-se que a incerteza expressa na proposição é atribuída à informante, pois, no momento da fala, ela já sabe o que aconteceu. Ela refere-se à incerteza do outro no momento do acontecimento do evento. A interpretação se dá no limite estrutural do próprio período. Já no contexto seguinte, o contexto de irrealis é atribuído ao próprio falante, segundo seu conceito de valor. 
(5) ... mas um dia eu ia querer ter um filho, e pra mim era como se eu PEGASSE um revólver, e TIVESSE matado um filho meu. (L. 24-25)

Se comparado a (4), percebe-se que o grau de irrealis em (5) é maior, chegando à escala do improvável numa espécie de seqüência de eventos que se apresentam ao interlocutor modalizados (BACK et al., 2005). Essa situação está ancorada no discurso para além do período, reafirmada pelos enunciados verbais "ia querer" e "era", que, nesse caso, contribuem para acentuar ainda mais o improvável, culminando com uma interpretação mais irrealis no contexto seguinte, no qual está inserido "tivesse", pressupondo-se uma gradação a exemplo de Coan (2003) ao postular a escalaridade [+ realis] a [+ irrealis], para a interpretação dos pretéritos mais-que-perfeito e perfeito. Além disso, vale ressaltar o fato de que a informante não fez o aborto. O enunciado remete a uma situação de dúvida no passado, mas não mais no presente.

Entretanto, a modalidade irrealis não se esgota no limite do (ir)real e/ou do (im)provável, mas se estende a possibilidades de interpretação metafórica da expressão temporal a serviço do efeito de sentido que o enunciatário pretende dar ao enunciado.

O que está por trás da idéia de valores metafóricos para as formas verbais refere-se ao fato de se fazer uso de uma forma que, prototipicamente, estaria reservada a valores temporais primários (primitivos), secundários e até terciários, a fim de expressar outras idéias que não necessariamente envolvam tempo ou que não envolvam os tempos esperados. Como exemplo, podemos tomar 'a metáfora do distanciamento temporal' (COAN, 2002), e a metáfora do presente utilizada para atualizar fatos passados (BACK et al., 2005), ${ }^{15}$ como segue, respectivamente:

(6) É teima? Quem te ENSINARA! (Peças de comédias de costume. CÂNDIDO E CASTELO, 1973, apud MARTINS PENA, 10)

(7) Os defensores da opção Dirceu ARGUMENTAM que ele tem o perfil para a hora na qual há desordem na base governista e o embate com a oposição se acirra. O próprio Dirceu, porém, sabe que é difícil. (Diário Catarinense - Dirceu não sabe se volta - 16/5/2005)

Em suma, expressam-se eventos no passado/futuro visando a distanciálos da enunciação, e/ou presentificam-se eventos já passados com o intuito de atualizá-los. Similarmente às outras seções, Bello trata dos valores metafóricos 
e discute-os inseridos nas relações de coexistência (C), posteridade (P) e anterioridade (A).

Para Bello (1979 [1841]), a relação de coexistência está diretamente relacionada com as percepções atuais (factuais), ao passo que os pretéritos e futuros estão relacionados com a memória (sombras do passado) ou raciocínio (vislumbre duvidoso do que está por vir - não-factuais).

A característica de percepções mais vívidas, atuais, proporcionada pela relação de coexistência, pode ser usada para expressar situações passadas ou futuras com maior grau de certeza, com vistas a atualizar o fato como atual. Daí, utiliza-se um efeito de sentido que é prototípico de $\mathrm{C}^{16}$ para codificar situações temporais que, em outras circunstâncias, seriam expressas por A ou P. Trata-se de um uso metafórico, quando há a transposição do pretérito ao presente, por exemplo, segundo Bello (1979).

No caso de C para codificar A, não se trata de aplicação de regras, mas do uso, por exemplo, da forma presente com valor histórico no lugar da forma de tempo passado, daí tratar-se de metáfora. Para Bello (op. cit. p. 442 § 125129), o valor metafórico é eminentemente estilístico, "autorizado pela prática dos escritores mais elegantes" [trad. nossa].

As formas de coexistência também se prestam a expressar situações futuras a fim de presentificá-las, torná-las idílicas conforme o autor, com o intuito de exprimir, sobretudo, uma maior possibilidade de realização, embora, no plano da expressão, trate-se de fatos futuros. O autor afirma que o uso dessa transposição é freqüente para dar maior certeza às proposições, como nos exemplos do $\S 126$ de Bello (1979, p. 443) que citamos a seguir, mais uma vez a modalidade ativando a interpretação metafórica.

(8) "El mes que viene hay un eclipse de Sol."17

(9) “Mañana voy al campo." 18

Não nos ateremos aos outros usos metafóricos cujos valores sejam de coexistência, uma vez que já ilustramos, brevemente, o que Bello entende por VMs. O que nos interessa são formas de PIS que figuram sob a forma-sse em português que se correlaciona às formas_se e_ra, do castelhano, que pressupomos apresentar o mesmo comportamento no discurso com relação ao valor metafórico, considerando o traço de anterioridade, como se observa na proposta de Bello $(1979,1984)$ cujos valores correspondem à A (pretérito), CA 
(co-pretérito), PA (pós-pretérito), AA (antepretérito), ACA (ante-co-pretérito), APA (ante-pós-pretérito), ligados aos subjuntivos comum e hipotético.

\section{Metáfora como expressão de valor atribuída à forma _sse}

Um dos traços pertinentes que viabilizam a leitura metafórica no caso da transposição das formas de pretérito (A) é a negação indireta, ou seja, dizer que uma coisa foi é dizer que não o é mais. Na verdade, faz-se uso da anterioridade não para afirmar algo que se passou, mas para negar uma condição que se faz presente. Vejamos o exemplo de Bello (1979, p. 446 § 142):

(10) a. Se ele tem poderosos protetores, conseguirá sem dúvida o emprego

b. Se ele tivesse poderosos protetores, conseguiria sem dúvida o emprego. ${ }^{19}$

Enquanto no primeiro período, em (10a), observa-se uma certa expressão de dúvida quanto ao fato ter poderosos protetores, no segundo, (10b), o pressuposto é o de não tem poderosos protetores e esse efeito de sentido é possível a partir do traço de anterioridade que assume. O papel da anterioridade aqui é, antes de expressar o tempo, afirmar que o fato de não ter poderosos protetores fará com que não tenha emprego, daí o autor atribuir o valor metafórico em situações como esta.

Para ele, a substituição não faz variar a idéia de tempo, pois o ter, a exemplo do que ocorre com a primeira proposição do par, é um verdadeiro presente, e o conseguir, um futuro, considerando a inter-relação entre os dois eventos no eixo temporal; daí toma-se emprestado da forma de PIS apenas o traço que esboça a relação de anterioridade para se obter a negação indireta (BELLO, 1979 [1841]). Trata-se de um tipo de estrutura condicional que faz uso da forma verbal pretérita não para expressar o tempo prototípico, mas para estabelecer a negação indireta.

Além de se estabelecer como foco principal a negação indireta, há ainda um matiz de sentido atribuído ao tom de moderação com o objetivo de não parecer, por parte de quem enuncia, presunção. Sobretudo, dando a entender que se tem por certo o que se está por dizer daquela realidade. Se não houvesse preocupação com o tom no sentido de proteger a face daquele de quem se fala, o enunciado poderia ser: 
(11) Ele não conseguirá o emprego por não ter amigos poderosos.

Segundo Back e Souza (2001, p. 109), uma das situações que faz com que a condição possa ser irreal é aquela que diz respeito ao fato de jamais poder realizar-se, por ser algo que contraria totalmente nossos conhecimentos. A estrutura [se + oração] reveste-se de uma forma condicional para expressar a certeza da não-realização da ação, conforme Bello (op. cit., § 142), via interpretação metafórica, ou de o fato ser irreal, conforme Back e Souza (op. cit.).

Bello, em sua conclusão, afirma sobre os valores metafóricos que "de estas metáforas accidentales de las relaciones de tiempo ofrece muchos ejemplos la lengua, y sería prolijo, o, por mejor decir, imposible, enumerarlas todas." (1979 [1841], p.457) $)^{20}$

O propósito deste trabalho, explorar os VMs do PIS, vem ao encontro da afirmação anterior. As relações de tempo podem nos mostrar inúmeros valores metafóricos. Neste estudo, durante a análise dos dados de fala, com base em amostra restrita, além do sentido de negação indireta, mais dois outros valores metafóricos foram evidenciados: 1) condição exclusiva e 2) falsa condição, os quais serão retomados no final desta seção.

Considere-se, primeiramente, o exemplo (12):

(12) [O que] eu gostava tanto [da] [da] [de] assim, de leitura que acabava lendo, assim, mas E gostava de todas. Então, não tinha nenhuma, assim, especial, né? que era uma leitura gostosa Minha mãe ficava doida, ela achava o cúmulo ler aquilo ali, é um absurdo, né? Queria que LESSE outras coisas, já que eu gostava de ler e que LESSE alguns livrinhos, né? infantis, comprava. Mas eu sempre recortava os livros todos, né? ... [VAFL01]

No dado apresentado em (12), há duas seqüências com lesse que possuem como ponto de referência o pretérito imperfeito (queria). Na primeira, pode-se dizer que se trata de um valor co-pretérito, pois lesse não exclui o queria, de modo que eles se entrecruzam. Entretanto, o valor mais evidente é o de que o leitor em questão não lia outras coisas. A segunda seqüência ratifica a primeira e pontua que não lia livros. Temos aí um valor metafórico cujo foco é a negação indireta do que se afirma. Trata-se da ocorrência, no português, do mesmo valor encontrado por Bello para o castelhano.

É interessante observar que, nesse dado, o valor metafórico não se reveste propriamente de uma estrutura condicional [se +oração]. A primeira estrutura 
apresenta-se como oração subordinada substantiva objetiva e a segunda, do ponto de vista sintático, como uma estrutura coordenada sem considerarmos a locução conjuntiva já que. Assim, teríamos, segundo essa interpretação, uma oração principal (queria) mais duas objetivas diretas coordenadas, como segue na transformação:

...queria que LESSE algumas coisas e que LESSE alguns livrinhos....

Entretanto, pode-se considerar uma outra possível interpretação em que a segunda oração, tida estruturalmente como objetiva direta, coordenada à anterior, seja, do ponto de vista semântico, uma conseqüência de uma estrutura causal iniciada pelo já que, como desdobramos a seguir:

(14) Já que eu gostava de ler, que LESSE alguns livrinhos, né?

O tom expresso tanto em (13) quanto em (14), ainda assim, mostra que o leitor não lia livros evidenciando a negação indireta como valor metafórico. Ao fazermos uso do PIS nesse contexto, até poderíamos substituir a locução conjuntiva já que pela conjunção condicional se com vistas a caracterizar o valor modal relativo à negação e não meramente à gradação de certeza. Vejamos:

(15) Se eu gostava de ler, que LESSE alguns livrinhos, né?

Isso revela que o traço de incerteza provocado pela estrutura condicional $(s e+$ oração $)$ é irrelevante nesse caso, pois o que interessa é negar, é dizer $e u$ não gostava de ler livros. É o que se observa no exemplo seguinte, também extraído do nosso corpus.

(16) F ... E daí, a gente foi até o juiz pra registrar, e a mãe foi deixar ela me registrar. Quer dizer que aí, se a mãe TIVESSE me REGISTRADO, eu seria legalmente filha dela, né? Não! Chegou lá, aí ela queria me levar, aí o juiz perguntou com quem eu queria ficar, aí eu começava a chorar e dizia que não queria ir embora com ela, não. Aí [eu vim] a gente veio embora, mas eu fiquei registrada no nome dela. E eu toda vida odiei [o meu nome] o meu sobrenome. [VAFL03]

Tivesse me registrado é anterior ao fato de ser legalmente filha, e visto que seria é pós-pretérito (futuro do pretérito), segundo Bello, temos um tivesse codificado como um ante-pretérito. Entretanto, o que é saliente na proposição veiculada no dado em (16), novamente é a idéia de negação do fato, que se reveste de uma estrutura condicional, daí o valor metafórico. 
Lembramos, ainda, que a amostra constituiu-se de quatro entrevistas de narrativas pessoais, nas quais encontramos oito dados com VMs, seis deles apresentando esse valor de negação indireta. Os dois outros apresentaram valores metafóricos distintos, a saber: 1) condição exclusiva e 2) falsa condição. Faremos a discussão de cada um, respectivamente, conforme os dados a seguir:

(17) ... Brincadeira de jogar no buraco, tinha brincadeira de jogar no buraco. Tinha que pular o buraco, quem não PULASSE tinha que ser jogado no buraco. E eu sempre era jogada dentro do buraco, né? e ficava lá.... [VAFL01]

Analisamos a forma pulasse com valor metafórico, tomando como referência a forma tinha que ser jogado. $\mathrm{O}$ ato de pular é anterior ao de ser jogado, a negação de um dos pares é a afirmação de outro. Nesse caso de a informante reportar uma situação dizendo quem não pulasse, tinha que ser jogado no buraco equivale a interpretar a ação deslocando-se para a situação reportada como quem não pula é jogado no buraco, portanto estamos na presença de um valor metafórico com o propósito de asseverar. É ponto pacífico: ou pula ou é jogado. Talvez a negação crie esse efeito de sentido que é o da exclusão de uma das ações, daí não podermos tratar somente de uma condição, ou seja, uma das asserções é negada:

(18) Se pular, não é jogado.

Se não pular, é jogado.

Portanto, não podemos simplesmente codificar como co-pretérito (coexistência pretérita), porque o ato de não pular é anterior ao ato de ser jogado, logo não são concomitantes. Na verdade, são mutuamente exclusivos. Segundo Bello (1979 [1841]), para ser co-pretérito, em algum ponto do eixo temporal deve haver cotemporalidade. Vejamos também o exemplo (19):

(19) $\ldots \mathrm{a}[<\mathrm{mi}>]$ irmã dele ainda era pior do que eu, ainda, na exigência [da] de limpeza. A irmã dele era ainda pior do que eu. Então era assim, [que o] se a gente jantasse ou almoçasse, que seja, [eu já] [eu já não era] eu não me sentava...Então [eu nunca] eu nunca tinha tempo pra ele, eu nunca tinha tempo pra ele e nem dava tempo pras crianças...Se TIVESSE tudo ARRUMADINHO, mas eu estava sempre arrumando alguma coisa pra fazer...eu acho que eu era doente por causa desse negócio de limpeza. [As gurias tudo] Até as minhas colegas assim sempre, elas, até às vezes, diziam pra mim. Hoje elas ainda dizem pra mim que como é que eu podia ser do jeito que eu era. [VAFL03] 
A pista para que atribuíssemos um valor metafórico ao dado apresentado em (19) foi a conjunção adversativa mas, que está acrescentando uma idéia de contraste. Se for assim, como seria possível agregar a uma estrutura de condição a idéia de contraste que está no campo semântico? Na verdade, não se trata de uma condição, mas de uma afirmação vestida estruturalmente de condição. Novamente, entra em cena o jogo da modalização, uma espécie de eufemismo fazendo uso da forma estrutural de uma condição para afirmar categoricamente, como se observa a seguir:

(20) Estava tudo arrumadinho, mas eu sempre estava arrumando mais alguma coisa....

Essa interpretação acarreta em um novo valor metafórico que chamamos de falsa condição $0^{21}$ por se apresentar, do ponto de vista estrutural [se + oração], como uma condição quando, na verdade, se trata de uma afirmação.

A partir do mapeamento do subjuntivo no que diz respeito à forma_sse, correlacionando-o ao subjuntivo comum e aos VMs, em se tratando da certeza veiculada pelas proposições como expressão de valor, podemos pensar na seguinte estratégia:

$\rightarrow$ Se a afirmação leva à afirmação = subjuntivo comum

$\rightarrow$ Se a negação leva à negação = subjuntivo comum

$\rightarrow$ Se a afirmação leva à negação = valor metafórico

$\rightarrow$ Se a negação leva à afirmação = valor metafórico

Com base no exposto até aqui, com relação ao traço de certeza e valores assumidos pelo PIS, propomos um percurso de ampliação semântica para o subjuntivo que delinearemos nas considerações finais.

\section{Considerações finais}

Bello se propôs a explicar a língua como expressão do pensamento. Assim, percebemos que vocábulos como metafísica, razão e entendimento são recorrentes na obra para explicar os atos mentais, o que evidencia seu vínculo com o ideal racional. "La nomenclatura que he adoptado representa las relaciones elementales según el orden en que se ofrecen al entendimiento"22 (BELLO, 1979 [1841], p. 427).

O fato de Bello explicar as relações temporais a partir do uso concreto da língua visa à importância de se poder comprovar a razão, entendida como um 
ideal puro. Daí estudar a língua de acordo com sua manifestação externa como forma de fortalecer, em alguma medida, os graus de abstração reservados à compreensão de como se estrutura o dizer.

O propósito de se explicar a língua com vistas a dar conta da expressão do pensamento faz com que percebamos no autor uma certa reflexão acerca dos processos cognitivos quando afirma que "la inteligencia humana ha procedido siempre de lo concreto a lo abstracto" (p. 418). ${ }^{23}$

Visando à relação concreto/abstrato, postulamos um caminho interpretativo para o subjuntivo no qual o percurso de ampliação semântica vai do concreto ao abstrato num primeiro momento e depois volta ao concreto com variação de sentido causada por intenções distintas como o não-comprometimento com o que se afirma, por exemplo. Vejamos o quadro (4) que ilustra o percurso:

\section{QUADRO 4}

Percurso de ampliação semântica para o subjuntivo

\begin{tabular}{l|c|l}
\hline & ESTRUTURAS SUBJUNTIVAS \\
\hline $\begin{array}{c}\text { Subjuntivo comum } \\
\text { - concreto }\end{array}$ & $\begin{array}{c}\text { Subjuntivo hipotético } \\
- \text { abstrato }\end{array}$ & \multicolumn{1}{c}{ VM - concreto } \\
\hline Condição [+ certeza] & Condição [- certeza] & $\begin{array}{l}\text { Condição exclusiva [+ certeza] } \\
\text { Comparação [+ certeza] }\end{array}$ \\
& & $\begin{array}{l}\text { Falsa condição [+ certeza] } \\
\text { Negação indireta [+ certeza] }\end{array}$ \\
\hline
\end{tabular}

A modalidade que expressa o grau de certeza está correlacionada com o processo de metaforização que se efetiva no final do percurso. Esse percurso se inicia com o subjuntivo comum expressando [+ certeza] em que se observam construções condicionais factuais ao lado de comparativas; passando, então, pelo subjuntivo hipotético por meio do qual as estruturas condicionais esboçam [certeza] em expressões não-factuais; por fim, os enunciados com forma_sse, que não se enquadram no subjuntivo comum ou no subjuntivo hipotético, figuram em estruturas condicionais esboçando o traço de [+ certeza], mas sem relação com o subjuntivo comum por colocarem em evidência não mais o tempo, mas a própria "atitude (modus) tomada pelo falante para com o conteúdo (dictum) que enuncia" (DUCROT; TODOROV, 1972) a certeza veiculada pelas proposições quanto à realização ou não dos eventos. As setas indicam o movimento da língua em que o processo se mostra de forma dinâmica e cíclica.

Sintetizando, no subjuntivo comum, a idéia seria: dada uma certa condição, há ou não a realização do fato. No subjuntivo hipotético, dada uma condição 
incerta, não se sabe se realizará tal asserção. Por fim, nos VMs, a certeza se reveste de uma estrutura condicional para modalizar o enunciado, afirma-se sem se comprometer. Neste último caso, a certeza é garantida por meio da pressuposição.

\section{Notas}

${ }^{1}$ The Varsul project involves four universities at the extreme south of the country (UFSC, UFPR, UFRGS and PUC-RS) and has as its main objective to investigate and describe the variation and changing phenomena observed in the communities of the South.

${ }^{2} \mathrm{O}$ projeto VARSUL envolve quatro universidades do Sul do país (UFSC, UFPR, UFRGS e PUC-RS) e tem como objetivo investigar e descrever fenômenos de variação e mudança nas comunidades do Sul.

${ }^{3}$ Nas sutis e efêmeras analogias de que depende a eleição das formas verbais (e outras tantas que possam ser atribuídas a outras partes da linguagem), encontrase um encadeamento maravilhoso de relações metafísicas, entrelaçadas com uma ordem e uma precisão que surpreendem quando se considera que se devem inteiramente ao uso popular, verdadeiro e único artífice das línguas.

${ }^{4} \mathrm{O}$ conceito de relação de tempo complexa em Bello nada tem a ver com a forma do verbo ser simples ou composta, mas com aquilo que podemos correlacionar a tempo absoluto e relativo, cf. Comrie (1990). Os absolutos têm o momento de fala, coexistência (C), como ponto de referência, a exemplo de passado (A) e futuro (P). Assim, que o tempo verbal absoluto é aquele que inclui como parte de seu significado o momento presente, cf. observa Coan (2002, p. 88), como centro dêitico (COMRIE, 1990). Já para interpretar os tempos verbais relativos, há que se levar em consideração não só o momento presente, como também e, por vezes somente, outro ponto no tempo, dado pelo contexto, como ponto de referência, daí sua complexidade.

${ }^{5}$ Co-pretérito equivale ao pretérito imperfeito dos modos indicativo e subjuntivo no português, ou seja, Bello chama de CA ao pretérito imperfeito do indicativo e subjuntivo. Encontramos tais valores também nas formas verbais do português, então o que se está fazendo é a transposição para o português.

${ }^{6}$ A mesma transposição referida na nota anterior se aplica: a interpretação do póspretérito equivale não só ao futuro do pretérito do indicativo, como também é percebida em contextos do pretérito imperfeito do subjuntivo. 
${ }^{7}$ Para Bello (1984 [1847], p. 200), cada forma verbal tem sua expressão de tempo, chamada de "valor fundamental", e outras expressões dele derivam segundo certas regras, chamadas de valores secundário e metafórico. O presente, por exemplo, significa coexistência com o ato da palavra e, mediante certas regras, pode assumir, como valor secundário, a expressão de futuro em certos contextos.

${ }^{8}$ Os antigos não imaginaram que a zona tórrida fosse habitável?

${ }^{9}$ Disseram-me (os mercadores murcianos a D. Quixote) que lhes mostrasse aquela senhora, que se ela fosse tão bela como dizia, de bom grado, confessariam a verdade. 10 “...a morte lhe desse

Com minhas mãos se pudesse"

${ }^{11}$ Discutiremos em mais detalhes a negação indireta implícita, segundo Bello, na seção seguinte.

${ }^{12}$ Tem-se a preocupação com o interlocutor no sentido de não exercer para com o outro a arrogância, o autoritarismo.

${ }^{13} \mathrm{O}$ nível discursivo envolve tanto o contexto multiproposicional, estabelecendo redes significativas e propiciando interpretação semântica, quanto o contexto que mobiliza recursos extralingüísticos decorrentes dos aspectos pragmáticos. Para tanto, faz-se referência a Moura (1999, p. 67) ao observar dois tipos de informação a serem consideradas: a primeira é a informação discursiva que envolve dados sobre o próprio fluxo do discurso e da conversação; a segunda, denominada informação sobre o mundo, envolve questões sobre os fatos, processos, indivíduos e objetos no mundo.

${ }^{14} \mathrm{O}$ contexto é de uma gravidez inesperada em que a informante narra um período de sua vida em que, ao saber de sua gravidez, fica atônita sem saber o que fazer. Sua melhor amiga, diante da notícia, sugere a ela que faça um aborto. Trata-se da entrevista 20 do projeto VARSUL de Florianópolis.

${ }^{15}$ Comunicação entitulada Tempo-aspecto-modalidade nos gêneros crônica, carta comercial, notícias e entrevista sociolingüística: a transposição didática, apresentada no III SIGET (2005) - Simpósio Internacional de Estudos dos Gêneros Textuais - Santa Maria - RS com publicação. A bibliografia completa consta nas referências bibliográficas.

${ }^{16}$ Lembramos que $\mathrm{C}$ corresponde à coexistência à enunciação, bem como $\mathrm{A} e \mathrm{P}$ ao passado e futuro, respectivamente.

${ }^{17}$ No mês que vem há um eclipse do Sol.

${ }^{18}$ Amanhã vou ao campo. 
${ }^{19} \mathrm{O}$ exemplo original é Si él tiene poderosos valedores, conseguirá sin duda el empleo.

${ }^{20}[. .$.$] destas metáforas acidentais das relações de tempo oferece muitos exemplos$ da língua, e seria prolixo, ou, melhor dizendo, impossível, enumerá-los todos.

${ }^{21}$ Em simpósio apresentado no GEL, uma colega de comunicação coordenada, Mariléia Reis, questionou-me se não seria mais apropriado chamar de falsa adversativa. Disse a ela que o contexto discursivo não encerra a idéia de contradição. Por fim, chegamos à conclusão de que mesmo que coubesse um outro nome a essa situação, ainda assim teríamos um valor metafórico, o que reforça ainda mais a argumentação dada à análise.

${ }^{22}$ A nomenclatura que adotei representa as relações elementares segundo a ordem em que são oferecidas ao entendimento.

${ }^{23}$ A inteligência humana sempre procedeu do concreto ao abstrato.

\section{Referências Bibliográficas}

BACK, Eurico; SOUZA, Ana Claudia. Prática de leitura e produção de texto. Criciúma: UNESC, v. 2, 2001.

BACK, Ângela et al. As categorias verbais tempo, aspecto, modalidade e referência: pressupostos teóricos para uma análise semântico-discursiva. In: III SIMPÓSIO INTERNACIONAL DE ESTUDOS DE GÊNEROS TEXTUAIS, 2005, Santa Maria. Anais III SIGET. Santa Maria: UFSM, 2005. (publicação eletrônica)

BACK, Angela et al. Tempo-aspecto-modalidade nos gêneros crônica, carta comercial, notícia e entrevista sociolingüística: a transposição didática. (No prelo.)

BACK, Angela. Temporalidade no pretérito imperfeito do subjuntivo. (No prelo.)

BELLO, Andrés. Gramática de la lengua castelhana destinada al uso de los americanos. Madrid: EDAF, 1984 (1847).

. Análisis ideológico de los tiempos de la conjugación castelhana. In: Obra literaria. Caracas: Ayacucho, 1979 (1841).

COAN, Márluce. As categorias tempo, aspecto, modalidade e referência na significação dos pretéritos mais-que-perfeito e perfeito: correlações entre função(ões)-forma(s) em tempo real e aparente. 2003. Tese (Doutorado em Lingüística) - Universidade Federal de Santa Catarina, Florianópolis, 2003. 
COAN, Márluce. $O$ uso do pretérito mais-que-perfeito simples como expressão do "Irrealis" nos "Autos da devessa contra os índios mura do rio Madeira e nações do rio Tocantins"; 2002; Comunicação; 5 CelSul - Cíclo de Estudos Lingüísticos do Sul; Fundação Araucária; Português; Universidade Federal do Paraná, Curitiba, 2002.

COMRIE, Bernard. Tense. 4. ed. Cambridge: Cambridge University Press, 1990.

DUCROT, Oswald; TODOROV, Tzvetan. Dicionário das ciências da linguagem. Lisboa: Publicações Dom Quichote, 1972. p. 365-378.

FIORIN, José Luiz. As astúcias da enunciação: as categorias de pessoa, espaço e tempo. São Paulo: Ática, 1996. p. 127-255.

GIVÓN, T. A functional-typological introduction. Amsterdam/Philadelphia: John Benjamins Publishing Co, 1984. v. 1.

. Verbal Inflections: Tense, Aspect, Modality and Negation. In: English Grammar: a functional-based introduction. Vol I e II. Amsterdam/ Philadelphia: John Benjamins Publishing Co, 1993.

LAKOFF, George. The contemporary theory of metaphor. In: ORTONY, A. (Org.). Metaphor and Thought. Cambridge: Cambridge University Press, 1993. p. 202-251.

LYONS, John. Semantics. Cambridge: Cambridge University Press, 1977.

MATEUS, Mira et al. A categoria lingüística tempo. In: Gramática da Língua Portuguesa. Coimbra: Livraria Almedina, 1983. p.104-153.

MOURA, Heronides Maurílio de Melo. Significação e contexto: uma introdução a questões de semântica e pragmática. Florianópolis: Insular, 1999.

REICHENBACH, Hans. Elements of Symbolic Logic. New York: Macmillan Company, 1947.

SOUZA, Ana Cláudia. ¿Pretérito imperfeito do subjuntivo? Formas verbais em _sse em contextos que veiculam a noção de posteridade. In: Working papers em Lingüística, UFSC, n. 5, p. 91-110, 2001. 